\title{
FIDES IMPLICITA: CANDIDATOS RELIGIOSOS NAS ELEIÇÕES MUNICIPAIS DE 2000 EM PORTO ALEGRE
}

\author{
André Marenco dos Santos \\ Professor de Ciência Política da \\ Universidade Federal do Rio Grande do Sul
}

Para Anthony Downs, os partidos constituiriam, nas democracias contemporâneas, um recurso capaz de promover "economia de informação": não preciso conhecer em detalhes cada programa partidário e sua alternativa para cada problema, bastando que assimile o significado dos rótulos ideológicos, consubstanciados em cada etiqueta partidária, para antecipar, com alguma segurança, o tipo de políticas que serão promovidas por cada um. Contudo, aos olhos do mais comum dos eleitores, partidos parecem entidades distantes, cujas diferenças seriam por demais abstratas para quem vive por referência à realidades concretas e imediatas.

A capacidade dos partidos em formar identidades e estruturar o voto é, sobretudo, resultado do tempo. Eleição após eleição, em um processo que quase sempre atravessa gerações, eleitores incorporam o significado de cada legenda partidária, assimilando seus símbolos e apelos, após a observação rotineira de sua ação, na oposição e no governo. Trata-se de uma espécie de "ortopedia política" (Offerlé, 1985), na qual partidos não apenas dizem o que eleitores identitários querem ouvir, mas criam os eleitores que desejem ouvir aquilo que eles tem a dizer-lhes. "Partidocracias" apresentam biografias partidárias longevas: no Uruguai, dois dos maiores partidos (Colorado e Nacional) descendem de facções e rivalidades que remontam o início do século, e o terceiro (a Frente Ampla) alcança 3 décadas de organização; na Argentina, cem anos de vida da UCR e cinquenta, dos peronistas, produziram marcas fortes o suficiente para sobreviver a todos os abalos sociais e políticos; por fim, no Chile, as três vertentes partidárias básicas estão em cena desde - ao menos - o início do século.

Em contraste, o sistema partidário brasileiro apresenta uma marca 
congênita de descontinuidade temporal. Considerando períodos de competição poliárquica (descartando, assim, os simulacros partidários do Império, República Velha e anos 30), pode-se falar em presença de partidos nacionais e competitivos a partir de 1945. Contudo, quando apenas começavam a revelar sinais de sedimentação, adquirindo identidade e estrutura nacionais, foram (por esta mesma razão) substituídos pelo bipartidarismo. Este, conheceu sorte semelhante, sendo substituído por um novo multipartidarismo, que trouxe consigo fragmentação nominal e migração inter-partidária. Fenômenos que ampliam os custos para a rotinização de imagens políticas, associadas a cada legenda. A natureza federativa do sistema político brasileiro, concorre, igualmente, para tornar mais difícil a fixação de marcas políticas, capazes de gerar sólidas lealdades.

Se a legislação eleitoral sofre mudanças praticamente a cada eleição, um dos poucos dispositivos que sofreram poucas alterações foi o modelo de lista aberta, introduzido no Código Eleitoral em 1932. A eleição para o preenchimento de cadeiras parlamentares (deputados e vereadores) no Brasil é definida pela proporcionalidade de votos obtidos por cada partido. Dentro destes, serão eleitos os candidatos que alcançarem as maiores votações nominais, até preencher a cota proporcional de cada partido. Parece trivial, mas não é, considerando-se que o Brasil é uma das raras democracias que adotam o sistema de lista aberta ${ }^{1}$. Via de regra, o voto proporcional é acompanhado por lista fechada, quando o eleitor possui oportunidade unicamente para votar na legenda partidária.

O voto com lista aberta já foi acusado - com alguma dose de injustiça - por quase todas as mazelas do sistema representativo brasileiro. Deixando um diagnóstico mais acurado de lado, pode-se sugerir que este voto personalizado incrementa os custos para a fixação de identidades partidárias. Embora seja provável que, tendo votado em uma primeira ocasião por afinidade pessoal, com o tempo o eleitor associe este vínculo ao partido de seu escolhido, assimilando, como seu, este rótulo, dois expedientes tornam sua operação, no Brasil, peculiarmente difícil para

Além do Brasil, Finlândia, Peru (desde 1985), Equador (desde 1998) e Polônia adotam regra semelhante. (Mainwaring, 1999). 
a confirmação de lealdades partidárias. Por um lado, estratégias de migração inter-partidárias, que ganharam contornos endêmicos no pluripartidarismo corrente; ao seu lado, a oportunidade, singularíssima da experiência brasileira, de coligações em eleições proporcionais. Ambas, concorrendo para tornar, aos olhos de leigos no campo político, mais precárias as relações entre candidatos e partidos.

Neste terreno em que o campo político não produz significados reconhecíveis, a concorrência pelos "profanos" beneficia aqueles que podem converter o voto em um ato de fé, como bem observou Oro: "votar além do dever cívico, na medida em que o gesto de votar assume o significado de um rechaço do mal que se instalou na política e sua substituição pelo poder do bem, introduzindo nele, mediante o voto, pessoas convertidas ao evangelho" (Oro, 2001).

A relevância adquirida pelo voto religioso e a formação de bancadas parlamentares evangélicas não corresponde à experiência - sobretudo européia, mas também chilena - da formação de clivagens profundas, que remontam à formação dos respectivos Estados Nacionais, e que legaram conflitos entre Estado/Igreja ou entre Igrejas nacionais e a autoridade supra-nacional da Igreja Católica. Na França, por exemplo, a frequência da prática religiosa constitui um preditor sobre as tendências de voto nas eleições presidenciais em cada região (Gaxie, 1985). Da mesma forma, prática religiosa representou, por mais de 4 décadas, um bom indicador do voto democrata-cristão na Itália (Spreafico, 1989).

A expressão residual de partidos confessionais no Brasil (DemocrataCristão, Social-Cristão) e a relação moderada entre identidade religiosa e o voto em eleições majoritárias ${ }^{2}$, indicam que candidaturas do campo religioso tem adquirido saliência particularmente em eleições proporcionais. É provável que o mecanismo de lista aberta atenue a expressão de identidades religiosas (e outros grupos expressivos). Fosse outra modalidade de voto, como lista fechada, e, provavelmente, as lideranças religiosas teriam que adotar uma estratégia de

\footnotetext{
${ }^{2}$ Embora a associação entre religião e voto presidencial mostre que certas confissões religiosas apresentem uma tendência para escolha de candidatos conservadores, não parece haver discrepância significativa entre esta inclinação e o comportamento apresentado pela maioria do eleitorado (ver a respeito Pierucci \& Prandi, 1996; Mainwaring, Meneguello \& Power, 2000).
} 
competição eleitoral visando fixar-se em uma legenda partidária própria, acentuando suas fronteiras com os demais partidos. O que eventualmente os levaria a apresentar candidaturas majoritárias vinculadas a um discurso religioso. A mobilidade permitida pela configuração lista aberta/migrações/coligações proporcionais evita a necessidade da adoção de estratégias de alto risco como esta, permitindo um recorte mais delimitado dos eleitores, preservando a intensidade dos vínculos entre a oferta política e a expectativa dos consumidores político-religiosos.

Aimagem projetada do eleitor, pelos estudos de comportamento eleitoral, sugere-nos, com frequência, uma entidade com traços de esquizofrenia política. Por um lado, as informações recolhidas por surveys de opinião e comportamento político revelam indivíduos - em especial aqueles de baixa renda e escolaridade despojados de preferências consistentes, incapazes de apreender o significado distinto de legendas partidárias ou ideologias políticas, ou mesmo de explicar as razões de suas escolhas eleitorais, e lembrar-se daquelas efetuadas em passado recente. A interpretação recorrente, oferecida por este instantâneo sugere um eleitor instável, flutuando de modo errático e imprevisível entre uma e outra eleição. Contudo, o exame do produto efetivo do processo eleitoral - o voto - mostra uma imagem distinta, destacando a tendência à sedimentação nas preferências eleitorais.

O mistério reside, assim, em decifrar a zona de sombras existente entre a manifestação do eleitor em seu estado bruto, colhida "em um dia qualquer de sua vida", e seu enquadramento cada vez mais regular, em uma alternativa política previsível. Para dar conta deste enigma, é preciso em primeiro lugar, não subsumir todos os processos responsáveis pela produção de filtros e parâmetros com os quais cada indivíduo julga as opções disponíveis: que estes não sejam fornecidos diretamente pelo campo político, mas se alimentem da matéria-prima fornecida por juízos morais, crenças religiosas ou afinidades pessoais, não limita sua relevância como valores que estruturam as escolhas políticas, tornando-as relativamente previsíveis. Mais importante, ainda, parece ser o recorte de todos os processos que não são capturados por surveys e outros instrumentos igualmente rigorosos de aferição de opiniões: contatos pessoais, redes sociais e políticas, círculos de amizades e toda a gama de influências trocadas entre indivíduos durante o "tempo da política" (Palmeira, 1996). Isto fica mais claro, quando descarta-se a suposição de um eleitor isolado, cujo voto seria a expressão, sem interferências externas, de 
suas inclinações. O mesmo eleitor, reconstituído nos surveys como "tábula rasa”, possui vizinhos, relaciona-se com parentes, amigos ou colegas de trabalho, frequenta uma Igreja. Vínculos cuja duração ultrapassa o calendário eleitoral. Na ausência de símbolos reconhecíveis fornecidos pelo campo político, estas relações serão a interface para a conexão deste eleitor com o mundo político. Aqui, a noção de "redes" (Sawicki, 1997) pode ser útil para decodificar as lógicas da concorrência e mobilização eleitoral.

Neste sentido, parece fértil a hipótese sugerida por Oro (2001) sobre a importância daestrutura organizacional como pista para compreender-se o sucesso/ insucesso das várias candidaturas religiosas nas eleições para a Câmara Municipal de Porto Alegre em 2000. Assim, a estrutura hierárquica da Igreja Universal, o rodízio promovido entre os pastores em cada templo e a eficácia em assegurar o engajamento de seus fiéis nas candidaturas apoiadas pela organização, constituiriam o capital distinto, possuído pelos políticos vinculados à Igreja Universal.

Um ângulo favorável para a observação do desempenho eleitoral dos candidatos religiosos pode ser obtido quando desagregam-se os votos segundo as zonas eleitorais que recortam o município. A distribuição espacial dos votos obtidos pelos candidatos vinculados a cada Igreja pode ser verificada através dos dados da Tabela 1:

\section{TABELA 1:}

Votos obtidos por candidatos vinculados à Igrejas Porto alegre, 2000

\begin{tabular}{lrrrrrrrrrr} 
ZONAIS: & $\mathbf{1}$ & $\mathbf{2}$ & $\mathbf{1 1 1}$ & $\mathbf{1 1 2}$ & $\mathbf{1 1 3}$ & $\mathbf{1 1 4}$ & $\mathbf{1 5 8}$ & $\mathbf{1 5 9}$ & $\mathbf{1 6 0}$ & $\mathbf{1 6 1}$ \\
\hline Universal & 1268 & 852 & 1345 & 1499 & 1775 & 2155 & 3409 & 3625 & 1162 & 1654 \\
Assembléia Deus & 443 & 366 & 521 & 655 & 590 & 846 & 1654 & 1678 & 962 & 1137 \\
Quadrangular & 62 & 31 & 62 & 42 & 88 & 244 & 58 & 129 & 947 & 670 \\
Batista & 108 & 105 & 323 & 266 & 86 & 102 & 581 & 68 & 111 & 205 \\
Adventista & 16 & 11 & 12 & 15 & 22 & 27 & 19 & 5 & 179 & 38 \\
Católicos & 879 & 1613 & 1213 & 706 & 643 & 471 & 287 & 1274 & 431 & 386 \\
Afro & 622 & 530 & 430 & 374 & 567 & 675 & 349 & 774 & 598 & 724 \\
\hline TOTAL & 3398 & 3508 & 3906 & 3557 & 3771 & 4520 & 6357 & 7553 & 4390 & 4814 \\
\hline \% voto religioso por zonal & 3,3 & 3,6 & 3,6 & 3,8 & 4,0 & 4,9 & 5,7 & 6,7 & 5,6 & 6,4
\end{tabular}

FONTE: Tribunal Regional Eleitoral RS. www.tre-rs.gov.br/eleições 
As Igrejas Universal e Assembléia de Deus recolheram votos distribuídos em toda a cidade, embora não deva passar desapercebido uma menor participação nas regiões centrais ( $1^{a}$ e $2^{a}$ Zonais), ao lado de uma frequência mais saliente em bairros da zona leste do município. Em contraste, candidatos católicos (em especial João Carlos Nedel) obtiveram melhor desempenho em zonas próximas ao centro (zonais $2^{\mathrm{a}}$ e $111^{\mathrm{a}}$ ). Por fim, o desempenho eleitoral de candidaturas das Igrejas Quadrangular e Adventista apresentou uma forte concentração de votos na zona sul, responsável por cerca de 2 em cada 3 eleitores conquistados. O resultado mostra um crescimento do voto religioso, à medida em que se afasta da região central da cidade, atingindo seus melhores escores nos bairros periféricos das regiões leste e sul.

A territorialização do voto adquire contornos mais precisos quando observa-se o desempenho eleitoral de cada candidato em cada zona eleitoral de Porto Alegre (Tabela 2). Em primeiro lugar, este procedimento permite confirmar a proposição de Oro, de uma divisão territorial entre os dois candidatos apoiados pela hierarquia da Igreja Universal: Valdir Caetano obteve seus melhores resultados em zonas situadas ao Norte da Avenida Ipiranga, como centro, Farrapos, zona norte e nordeste; paralelo, Almerindo ficou com as regiões sul e sudeste.

A topografia eleitoral do vereador Valdir Caetano apresenta suas coordenadas mais salientes em bairros das regiões Norte/Nordeste: começando pelo Sarandi, passando pela Vila Elizabeth, Safira, Santo Agostinho, Nova Santa Rosa, Parque dos Maias, atingindo a Chácara da Fumaça e estendendo-se até a vila Bom Jesus. Chama a atenção que o único templo da Igreja Universal em toda a extensão desta região localizase em uma de suas extremidades, próximo à vila Bom Jesus ${ }^{3}$.

Já o mapa eleitoral do vereador Almerindo distingue-se por sua configuração não-contígua, destacando 3 núcleos principais: Lomba do Pinheiro e Morro da Cruz, ao Leste; Cruzeiro e Santa Tereza no CentroSul; e vila dos Sargentos e Restinga, no extremo-sul.

O último eleito entre os candidatos com vínculos religiosos João Carlos Nedel - obteve $43 \%$ de seus votos em bairros que circundam o centro da cidade.

${ }^{3}$ Conforme informação extraída da home page da Igreja Universal: www.arcauniversal.com.br 


\section{TABELA 2:}

Distribuição dos votos de candidatos religiosos por zonais eleitorais - Porto Alegre, 2000

\section{ZONAIS}

\begin{tabular}{|c|c|c|c|c|c|c|c|c|c|c|c|}
\hline & 菢 & 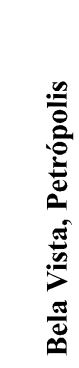 & 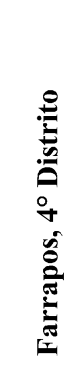 & 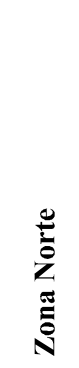 & تే & 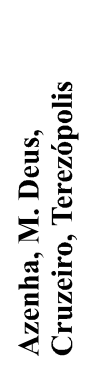 & 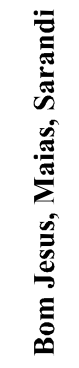 & 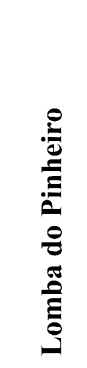 & 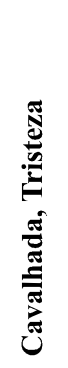 & 范 & \\
\hline CANDIDATOS: & 1 & 2 & 111 & 112 & 113 & 114 & 158 & 159 & 160 & 161 & TOT \\
\hline Valdir Caetano & 896 & 664 & 1192 & 1241 & 798 & 847 & 3119 & 1428 & 407 & 321 & 10913 \\
\hline Almerindo Rosa & 365 & 185 & 142 & 241 & 972 & 1303 & 167 & 2187 & 751 & 1332 & 7645 \\
\hline Varanice Neto & 7 & 3 & 11 & 17 & 5 & 5 & 123 & 10 & 4 & 1 & 186 \\
\hline Eliseu Sabino & 139 & 105 & 158 & 157 & 236 & 469 & 604 & 748 & 589 & 460 & 3665 \\
\hline Willis Taranger & 141 & 179 & 289 & 364 & 177 & 136 & 688 & 304 & 77 & 136 & 2491 \\
\hline Paulo Eliseu & 104 & 73 & 65 & 115 & 145 & 112 & 333 & 583 & 50 & 134 & 1714 \\
\hline Flávio Batista & 59 & 9 & 9 & 19 & 32 & 129 & 29 & 43 & 246 & 407 & 982 \\
\hline Nilo Santos & 62 & 31 & 62 & 42 & 88 & 244 & 58 & 129 & 947 & 670 & 2333 \\
\hline láudio Conceição & 108 & 105 & 323 & 260 & 86 & 102 & 581 & 68 & 111 & 205 & 1949 \\
\hline João Caetano & 16 & 11 & 12 & 15 & 22 & 27 & 19 & 5 & 179 & 38 & 344 \\
\hline João Nedel & 780 & 1574 & 1081 & 610 & 442 & 405 & 234 & 209 & 401 & 330 & 6039 \\
\hline Claudiomir & 99 & 66 & 132 & 96 & 201 & 66 & 53 & 1065 & 30 & 56 & 1864 \\
\hline Jorge Verardi & 156 & 76 & 86 & 143 & 185 & 274 & 154 & 235 & 285 & 400 & 1994 \\
\hline Beto do Nagô & 170 & 82 & 75 & 56 & 106 & 132 & 43 & 262 & 79 & 104 & 1109 \\
\hline
\end{tabular}

Fonte: Tribunal Regional Eleitoral RS. www.tre-rs.gov.br/eleições 
Por fim, vale a pena retomar a questão proposta por Oro, acerca da estratégia desenvolvida pelas lideranças da Igreja Universal, de aproximação com o PT, a partir do segundo turno das eleições municipais em Porto Alegre. A Universal revelou significativa capacidade de converter fiéis em eleitores, baseada em uma organização não apenas centralizada, como também capaz de no extremo de sua rede, impermeabilizar seus seguidores contra a dispersão de votos, tanto entre seus candidatos como face a outros apelos, não apenas religiosos. As fracas votações obtidas por candidatos de outras correntes religiosas sugerem sua fragilidade nesta direção, ou seja, encaminhar seus seguidores, do templo à urna.

Se isto evidenciou a força da Universal, também expôs sua fragilidade, pois os 18.744 votos conquistados por seus 3 candidatos representam, na verdade, apenas $2,2 \%$ dos votantes naquela eleição. Ambições mais amplas exigem, neste caso, estratégias mais ousadas. Em outras palavras, o desafio posto frente à expansão eleitoral da Igreja Universal será o de expandir a audiência de seus porta-vozes para além dos eleitores mais fiéis. Aqui, o controle hierárquico desta Igreja talvez possa representar uma camisa de força. Enquanto membros de outras Igrejas ocupam posições de liderança em partidos de esquerda, como o Governador Garotinho, e sua vice, Benedita da Silva, no Rio de Janeiro, a Senadora Heloisa Helena e o líder do PT na Câmara dos Deputados, Walter Pinheiro, o perfil político da Igreja Universal, fruto de seu próprio padrão mais disciplinado, terminou por associar-se, exclusivamente, com partidos/discursos à direita do espectro político. Manter este estigma implica em não abrir as portas para outros segmentos, seja pensando em metas eleitorais ou mesmo de ampliação da atração de fiéis para a Igreja.

De qualquer forma, pode-se projetar para o futuro a manutenção de um importante espaço de mobilização eleitoral a partir de vínculos religiosos. O que não deve ser visto com "maus-olhos": trata-se, na verdade, da forma através da qual, importante parcela do eleitorado integra-se ao jogo eleitoral, podendo sentir-se representado. Pluralismo, afinal de contas, é isto. 


\section{Referências Bibliográficas}

GAXIE, Daniel. Explication du vote: Un bilan des études électorales en France. Paris, Presses de la Fondation Nationale de Science Politique, 1985.

MAINWARING, Scott; MENEGUELLO, Rachel \& POWER, Timoty. Partidos conservadores en Brasil contemporâneo: o que são, o que defendem, quais são suas bases. São Paulo, Paz e Terra, 2000.

MAINWARING, Scott. Rethinking party systems in the third wave of democratization: the case of Brazil. Stanford University Press, 1999.

OFFERLÉ, Michel. "Mobilization électorale et inventon du citoyen: l'exemple du millieu urbain français à la fin du XIXeme. Siècle". IN: GAXIE, Daniel. Explication du vote: Un bilán des études électorales en France. Paris, Presses de la Fondation Nationale de Science Politique, 1985.

ORO, Ari Pedro. Religião e política nas eleições 2000 em Porto Alegre $(R S)$. Porto Alegre, mimeo, 2001.

PALMEIRA, Moacir. "Política, facções e voto”. In: PALMEIRA, Moacir \& Goldman, Márcio. Antropologia, voto e representação. Rio de Janeiro, Contra-capa, 1996.

PIERUCCI, Antônio Flávio \& PRANDI, Reginaldo. A realidade social das religiões no Brasil. São Paulo, Hucitec, 1996.

SAWICKI, Frédéric. Les réseaux du parti socialiste. Paris, Belin, 1997.

SPREAFICO, Alberto. "Structures sociales et comportement politique dans le Mezzogiorno". IN: LEVY, Ives (Org). Ideologies, partis politiques \& groupes sociaux. Paris, Presses de la Fondaction Nationale de Science Politique, 1989. 